\title{
Habits and the electronic herd: The psychology behind social media's successes and failures
}

\author{
Ian A. Anderson ${ }^{1}$ (i) | Wendy Wood ${ }^{2}$
}

${ }^{1}$ Department of Psychology, University of Southern California, Los Angeles, CA, USA

${ }^{2}$ Department of Psychology and Marshall School of Business, University of Southern California, Los Angeles, CA, USA

\section{Correspondence}

Wendy Wood, Department of Psychology and Marshall School of Business, University of Southern California, Los Angeles, CA, USA 90089.

Email:wendy.wood@usc.edu

\begin{abstract}
If platforms such as Facebook, Instagram, and Twitter are the engines of social media use, what is the gasoline? The answer can be found in the psychological dynamics behind consumer habit formation and performance. In fact, the financial success of different social media sites is closely tied to the daily-use habits they create among users. We explain how the rewards of social media sites motivate user habit formation, how social media design provides cues that automatically activate habits and nudge continued use, and how strong habits hinder quitting social media. Demonstrating that use habits are tied to cues, we report a novel test of a 2008 change in Facebook design, showing that it impeded posting only of frequent, habitual users, suggesting that the change disrupted habit automaticity. Finally, we offer predictions about the future of social media sites, highlighting the features most likely to promote user habits.
\end{abstract}

\section{KEYWORDS}

contexts, goals, habits, reward, social media, technology

\section{1 | INTRODUCTION}

Social media sites, also known as social networking sites, are widely used by consumers. Social media refers to online platforms that enable participating individuals and communities to communicate publicly or semi-publicly via user-generated profiles and content. Fully $72 \%$ of American adults used at least one social media platform as of 2019 (Perrin \& Anderson, 2019). Facebook alone boasted more than 2.6 billion active users (Statista, 2020)-almost a third of the world's population.

This impressive reach gives social media tremendous power over people's lives. In 2019, users engaged with social media an average of $2 \mathrm{hr}$ and 24 min per day worldwide (We Are Social, DataReportal, $\&$ Hootsuite, 2020). Use time per day has increased each year since 2012 and shows no sign of having peaked. Social media is also a tremendous revenue generator in the online marketplace. In one estimate, the average user on Linkedin generated $\$ 17.10$ in revenue in 2019, and the average user on Twitter generated \$9.22 (Digital
Information World, 2019). The breadth, depth, and financial impact of social media use highlight its importance for consumer behavior and marketing.

In the present article, we first explore the patterns of consumer behavior that are created by successful social media sites. We then explain and predict these patterns through the lens of psychological research on habit formation and performance. Habits are cognitive associations that people learn as they repeat rewarded responses (Amodio \& Ratner, 2011; Wood \& Rünger, 2016). Specifically, repeated users of social media learn to associate various cues in the performance context (e.g., site alerts, smartphones) with particular responses (e.g., logging on). Once habits have formed, perception of these cues automatically brings the practiced response to mind. In this way, habits streamline responding so that consumers automatically repeat what they have done in the past to gain rewards.

After demonstrating that consumer habits contribute to the success of social media sites, we discuss the rewards that social media provides to motivate repeated use and form frequent-use habits. 
Then, we discuss how social media provides context cues that come to automatically activate consumer use. The article then explains how habits keep consumers using social media sites even when they might want to reduce their use or quit. Finally, we apply our model of habitual social media use to make predictions about the future. We discuss how social media sites can maintain current popularity and speculate about site features that are likely to generate future success.

\section{2 | HABITS ARE PART OF SOCIAL MEDIA SUCCESS}

Unique in its meteoric rise and ability to capture hours of users' time, social media is a product with a large group of repeat customers. Repeated use is not just a side effect of social media's success but instead appears to be central to it. The critical role of daily users was first shown in a longitudinal survey of about 450 Microsoft employees that assessed their use of five social media sites between 2008 and 2011 (Archambault \& Grudin, 2012). User daily repetition was the difference between media sites that were ultimately successful and ones that failed. Specifically, across the 4 years of the study, Facebook, LinkedIn, and Twitter, which were all developing platforms at the time, increased not just the overall percentage of users but also the percentage that used them daily or more often. In contrast, MySpace, which was in 2008 the most popular networking site in the world, and Live Spaces, a Microsoft website, declined in both overall users and the percentage of daily users. Ultimately, Live Spaces and Myspace failed.

Surveys of the use patterns of major social media platforms echo this story: In a 2019 Pew report, Facebook led the way with $69 \%$ of American adults saying they used the site, followed by Instagram with $37 \%$ and Twitter with only 22\% (Perrin \& Anderson, 2019). Again, the more successful sites not only had greater reach among potential users but also had more intensive, daily users (see Figure 1): In 2019 $51 \%$ of Facebook users accessed it daily, $42 \%$ of Instagram users did so, followed by only $25 \%$ of Twitter users (Perrin \& Anderson, 2019).

The relation between frequent users and the success of social platforms is evident also with social media advertising revenue. We estimated the size of this relation across 6 years between 2013 and 2019 for Facebook, Twitter, and Instagram. Specifically, we computed correlations between the percentage of American users who accessed these sites several times daily (Perrin \& Anderson, 2019) and each site's U.S. advertising revenue in billions of dollars (i.e., total amount of paid advertising, eMarketer, 2020; note missing 2013 and 2014 revenue for Instagram). The percent of consumers who used a site several times daily was strongly correlated with that site's financial success, $r(14)=0.71, p=.003$, based on a hierarchical correlation, grouped by site (R Correlations, Makowski et al., 2020). To put these findings into perspective, other patterns of use, such as the percentage of users who accessed a site every few weeks, were not positively related to revenue. In fact, greater percentages of these occasional users were associated with lower site revenue. Thus,
Twitter Users' Self-Reported Use Frequency
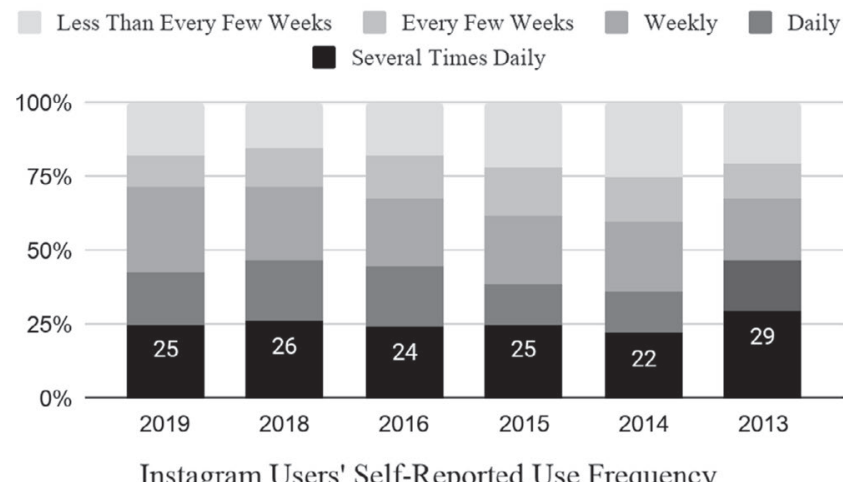

Instagram Users' Self-Reported Use Frequency
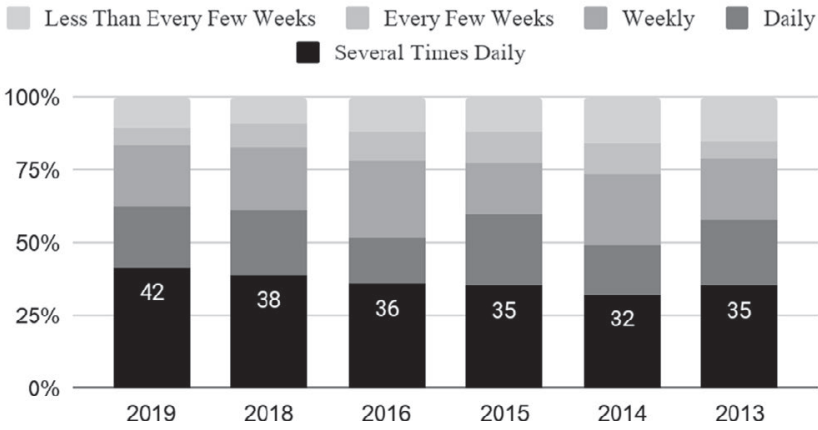

Facebook Users' Self-Reported Use Frequency
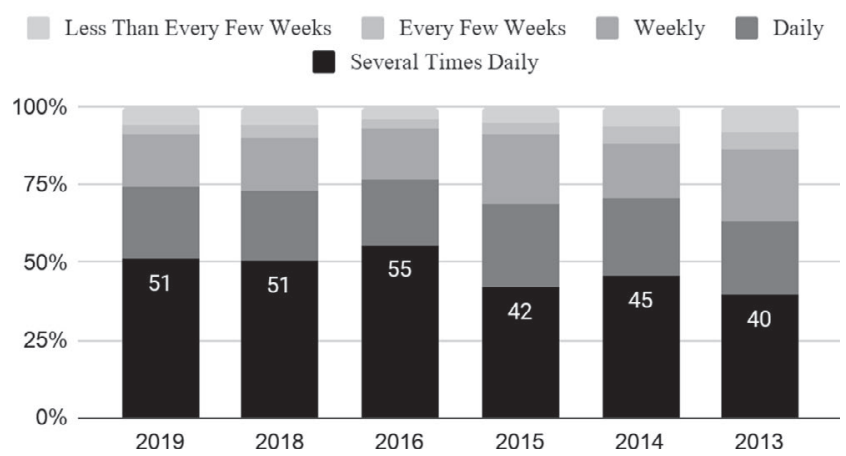

FIG URE 1 U.S. Frequency of Social Media Site Use. Note. Data from Pew Research Center (Perrin \& Anderson, 2019). Data were not available for 2017. Participants were U.S. adults, 18 years and over. Different respondents were included each year

supporting the longitudinal research with Microsoft employees, our analysis of cross-sectional data revealed that the financial success of social media platforms is closely tied to percent of frequent users. One explanation for this association is that success at marketing a social media product depends on building and sustaining repeated use habits among consumers.

\section{1 | Frequent use is habitual use}

To test whether frequent social media use does in fact reflect habit, we conducted several surveys with Twitter and Facebook users (recruited via the online platform, MTurk, and the research participant pool at a large Californian university, respectively, Anderson 
\& Wood, 2020). As we anticipated, frequent use is largely habitual use. That is, the frequency with which participants posted on a site was significantly related to the automaticity with which they did so, $r(124)=.46, p<.001$, for Twitter, and $r(60)=.50, p<.001$, for Facebook. Specifically, past posting frequency was positively associated with higher scores on the Self-Report Behavioural Automaticity Index (Gardner et al., 2012), a widely accepted indicator of habit strength. This 4-item scale includes questions such as, Tweeting/ Using Facebook is something "I do automatically" and "without thinking" (alphas $=.94$ and .83 , respectively).

Thus, media sites that were used more frequently were also used more habitually. This positive association between frequency of use and habit automaticity was further demonstrated in a longitudinal study across a month: Students who started to use a new sports app repeatedly also reported increasing automaticity of opening the app (Schnauber-Stockmann \& Naab, 2019). In short, consumers' frequent-use habits appear to be key to the market success of social networking sites.

\section{2 | Further defining habitual social media use}

A broad range of cues in performance contexts can activate habits, including site features (e.g., page layout), times of day, technology (e.g., smartphone), events (e.g., riding a bus), and mood (e.g., boredom). As we explained, consumers come to associate these with repeated use behaviors of logging in, posting, and giving likes/comments on others' posts. Once consumers have formed media use habits, the practiced response (e.g., logging in) is automatically brought to mind when they perceive the associated cues (e.g., a message alert). Then, through an ideomotor process, people tend to carry out the response in mind (James, 1890). In James's (1890) words, "every mental representation of a movement awakens to some degree the actual movement which is its object" ( $p$. 526). The result is that habit memories provide a useful mental shortcut for what behavior to perform in a given context that is likely to get rewarded.

Consumers initially form habits to use a site due to the rewards they gain for doing so, such as the social recognition of likes, followers, and friends. Yet, once habits form and site use becomes automated, consumers' motivations become less important. In this way, habits differ from motivational drivers of consumer behavior, such as brand loyalty and brand attitudes (Tam et al., 2009). As explained in the section, "Motivation fades as habits form," consumers continue to use sites habitually despite motivations to act otherwise (Limayem \& Cheung, 2008; Limayem et al., 2007). Thus, a habitual Twitter user might find themselves checking it automatically despite wishing to reduce their use. In an experiment demonstrating habit persistence despite conflicting attitudes, consumers continued to choose their habitual sugared beverages for a taste test even after reading a persuasive message that convinced them of the health risks of sugar (Itzchakov et al., 2018). In contrast, consumers without sugared-beverage habits acted on their new attitudes and avoided drinking sugary beverages. In another demonstration, food choice habits persisted independently of participants' implicit attitudes toward the food (Lin et al., 2015). Similarly, once consumers have formed habits to use a social media site, they tend to persist even when rewards shift or consumers' motivations change (see section, "Habits and Quitting").

Although this article refers to consumers as having or not having a social media use habit, readers should keep in mind that this oversimplifies habits in several ways. Social media use is not a unitary act but is actually composed of a variety of behaviors, each of which may become habitual to varying degrees. After logging on, consumers scroll, click, read, and react, and they post a variety of content with photographs, videos, and written thoughts. Given that habits form gradually through repeated experience, each of these responses can incrementally gain in strength with repetition. Indeed, research shows no clear demarcation when a habit has become strong rather than weak (Lally et al., 2010). In addition, habits integrate with other psychological processes in guiding media use, especially for more complex behaviors. For example, consumers might automatically log on and start to type while thoughtfully deliberating about what to post and how to frame it. In this way, even strongly habitual use of social media sites may be integrated with more deliberate decisions. Nonetheless, for simplicity, we refer to site users as responding more or less habitually.

\section{3 | FORMING HABITS: REWARDS FOR SOCIAL MEDIA USE}

Consumers start to use a social media site because of the rewards, or favorable outcomes, they gain from use. Given sufficient rewards, consumers form positive attitudes, or evaluative tendencies toward social media, along with favorable subjective norms, or social pressures to use it, and perceive use as frictionless, or easy, all of which contribute to favorable use intentions (Fishbein \& Ajzen, 2011). As we show, by promoting repeated use, these favorable reactions can ultimately lead to habit formation. Alternatively, negative attitudes, unfavorable subjective norms, and high friction lead to unfavorable intentions that motivate users to avoid social media.

To guide our analysis, we develop these ideas into the model of social media habit formation in Figure 2 that begins with users' intentions. As shown in the model, favorable intentions, in conjunction with friction, guide various responses on social media within particular contexts (depicted as the encompassing box) to achieve rewarding outcomes. In the next few sections, we explain each of these points in turn, beginning with intentions to achieve rewarding outcomes. Throughout, we also reference friction, or consumers' experience of delays and hurdles when accessing social media. By automating login and security verification and speeding load times, social media companies decrease consumers' friction and increase subsequent likelihood of use. When streamlined in these ways, initially trying social media is easier for beginning users and repeated use is easier for returning users. 


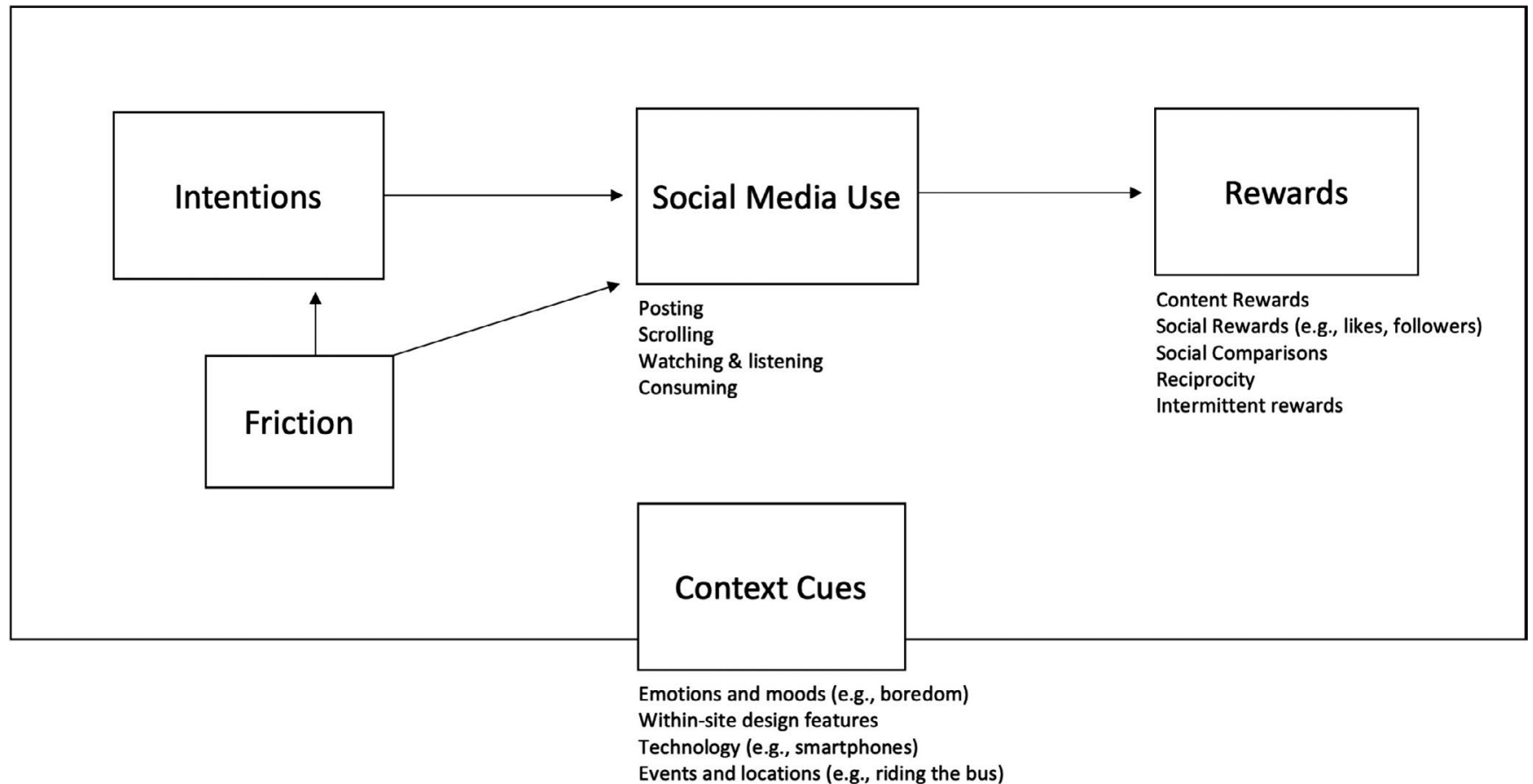

FIGURE 2 Model depicting social media habit formation. Note. Flow chart of habit formation process on social media, beginning with user intentions that guide specific use behaviors in order to obtain anticipated rewards, all within the contexts in which social media is used

Our account builds on prior models of media habits (Bayer \& LaRose, 2018), technology habits (LaRose, 2010; Venkatesh et al., 2012), and interactive media habits (LaRose, 2015). Yet, our focus on the psychology behind habitual social media use extends beyond classifying habit automaticity as a kind of ineffective self-regulation (LaRose, 2010). Instead, we recognize habit as an automatic response mechanism that forms through repetition and provides benefits as well as costs for individual users. In addition, we consider specific social media use behaviors (e.g., scrolling, posting, reacting, commenting) as habits in their own right, instead of classifying them under the umbrella term of use. In so doing, we identify how these behaviors become habitual and perpetuate consumers' engagement.

\section{1 | Rewards for using different social media sites}

Each social media site provides rewards attractive to a particular group of users. For example, Snapchat users reported a desire to pass time, share problems with others, and improve social knowledge (Phua et al., 2017). Adolescents find Snapchat especially attractive due to its privacy and live video and photograph sharing, not to mention the escape it may provide from older users (including parents) who are on Facebook and older social networking sites (Jaffray \& eMarketer, 2020; Snap \& Inc., 2019).

Journalists and newsmakers may be drawn to Twitter for its rewarding tips for their work and a real-time audience for brief thoughts. Twitter users had the highest scores among social platforms for being members of a brand community in the sense that they were open to connecting with brands on the platform (Phua et al., 2017). Other reasons for using Twitter are self-expression, escapism, and social interaction-in addition to a desire to share a social and political agenda (campaign gratification, Dindar \& Yaman, 2018). Illustrating a novel reward, Junco et al. (2011) used Twitter to demonstrate the academic benefits for students of using the site to engage with course material.

Instagram was the most popular smartphone-based social media app in 2019 (Perrin \& Anderson, 2019). Users reported wanting to show affection, follow fashion and celebrities or influencers, and demonstrate their own sociability (Phua et al., 2017; Snap \& Inc., 2019). They were also motivated by escapism, archiving photographs, and self-expression (Lee et al., 2015). In addition, Instagram users reported checking what friends and family are up to, killing time out of boredom, sharing with people in their lives, and seeking inspiration (Statista, 2020).

The largest social platform in the world, Facebook, remains the most popular site in the United States (Perrin \& Anderson, 2019). Facebook users reported overwhelmingly that the site helps them keep in contact with friends and family and to a lesser extent provides entertainment and news (AudienceProject, 2019). More specifically, users reported sharing and watching videos, photographs, and other content (eMarketer, 2019).

Individual consumers do not all experience the same rewards; instead, the rewards users receive depends on how media is used. For example, passive users, who largely scroll and read, report relatively lower subjective well-being compared with more active users who engage with others (Verduyn et al., 2015, 2017). In addition, experiences on a site are important. Users who get more likes and comments on posts also tend to have higher self-esteem and happiness (Zell \& Moeller, 2018). Furthermore, posting 
personal status updates on Facebook has been associated with reduced feelings of loneliness (Deters \& Mehl, 2013) along with increased feelings of social support (Seo et al., 2016). Thus, the rewards users actually receive from a site depend on how they use it, with greater experience of rewards associated with more active use, more positive reactions from others, and sharing personal information.

\subsection{Rewards common to most social media}

\subsection{1 | Content rewards}

A central reward on social media is content in the form of others' posts. Most social media sites present content through a scroll or incremental reveal of only a few posts at a time. With a scroll, posts that are particularly rewarding and pique users' interests are embedded within a set of less rewarding posts. In this way, scrolling increases users' experience of the uncertainty of content-based rewards, heightening the experiences of surprise and inconsistency with a site's content. Experimental research shows that habits build more readily from more valued rewards and less expected, more intermittent rewards (e.g., DeRusso et al., 2010). Thus, the scroll is a means of reward delivery that likely promotes media use habit formation.

The scroll's highlight of unexpected posts may encourage users to focus on and share content that violates expectations, such as highly emotional content (Brady et al., 2020), hedonic content (Köse, 2020), and even false information (Vosoughi et al., 2018). More emotional, hedonic, and false information spreads the farthest and fastest on social media (Vosoughi et al., 2018). Users may find these the most rewarding types of content to share, as they tend to spark conversation, capture attention, and spread broadly through others' shares (Brady et al., 2020).

Further heightening reward value, sites curate the content displayed for each user, using algorithmic optimization to better address their interests, needs, and worldviews (Docherty, 2020; Thorson et al., 2019). These machine-learning algorithms also purportedly contain some habit logic, such as integrating reward learning principles into content delivery (Rhodes \& Orlowski, 2020). For example, sites track individual use, especially clicks on featured or selected content (referred to as bait), in order to identify other potentially rewarding content to include in a feed (Rhodes \& Orlowski, 2020). The algorithms work by instrumental, or trial-and-error learning, to develop a profile of what individuals choose to see. They also use screen choices of other, similar users, which can create new desires while reinforcing existing ones (Noble, 2018).

\subsection{2 | Social rewards}

Social media's reward system is fundamentally social. After a post, other users give likes, comments, and notifications, which function as relatively public social rewards. Popularity is another reward, through visible follower or subscriber counts, as are displayed on Twitter and YouTube, respectively (Oh \& Syn, 2015). Demonstrating that posting is responsive to such rewards, Lindström et al.'s (2019) computational model that incorporated reward learning based on the likes and comments Instagram users received on their photographs was the best predictor of how often they posted. Thus, consistent with Figure 2, within-site social rewards are important for motivating site use.

The content provided by social media feeds as well as the reactions displayed to this content capitalize on users' desire to socially compare with others. Social comparison involves downward or upward evaluations of oneself relative to other people. Each piece of content presented in a social media feed is effectively a potential point of comparison. Downward comparisons might be incited by others' personal crises, one's own superiority in recognizing the latest trends, or gossip about celebrities (Chan \& Briers, 2019). Yet, upward comparisons are common given posters' positivity bias, or tendency to share favorable news about themselves (Spottswood \& Hancock, 2016; Utz, 2015). Such comparisons can yield negative effects, as for example social media with idealized images of lifestyles and body types exacerbate body image issues and low self-esteem among young women (Perloff, 2014). Thus, social comparisons can be leveraged as rewards, but they also carry risks for social platforms if users suffer from upward comparisons. For example, social comparisons that incited jealousy or bad feelings about users' personal circumstances have damaged some users' perceptions of Instagram (de Vries et al., 2018).

Beyond social comparisons, social media sites inherently offer the reward of participating in a forum to maintain relationships with friends and create new ones (Alhabash \& Ma, 2017). Having friends who already use a site is both an initial reward and a kind of social pressure that has been described as a gravitational pull that attracts new users though network effects (Aral, 2020). For example, Facebook's first VP of User Growth, Chamath Palihapitiya, argued that attaining the "north star" of one billion users required each new user to add at least seven friends in the first 10 days-a step that he believed would lead to retention (Biyani, 2013). Rewards from social connections extend to consumer relationships with brands. Users derive positive feelings from being part of a brand identity group and reported feeling positively rewarded by brand interactions when connected to others within the brand page (Vernuccio et al., 2015).

Social rewards on networking sites, as in other contexts, create reciprocity norms that magnify reward effects. Reciprocity reflects an exchange between two or more actors, generally for mutual benefit (Lewis, 2015). Facebook, for example, provides ticks to indicate when someone has read a message. When the original poster sees those ticks, they create social pressure to reciprocate in kind by reading and liking others' posts. Sites also send notifications of unread messages, which heighten pressures to reciprocate by reading others' posts. The pressure to respond in kind on social media is felt broadly, given that both frequent and occasional users of five leading social media sites reported that reciprocity was a primary motivator (Oh \& Syn, 2015). 


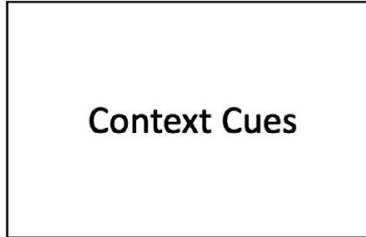

Emotions and moods (e.g., boredom)
Within-site design features
Technology (e.g., smartphones)
Events and locations (e.g., riding the bus)
FIGURE 3 Activation of Social Media Habits by Context Cues. Note. Flow chart of the activation of social media use habits, once formed. Perception of the context cues associated with past use brings thoughts of using to mind. Then, through an ideomotor process, consumers often act on the thought in mind
The kinds of rewards that social media provides are immediate in the sense that consumers experience them as part of accessing the site and exploring its content. Immediacy of rewards is important because of the way that brain systems register rewarding events. On experiencing rewards, neural systems release dopamine that helps to form habit associations between contexts and responses (Wood \& Rünger, 2016). The time scale of dopamine effects is brief, spanning at most a few seconds (Cohen, 2015). Thus, rewards that are temporally distant from an activity, like sending follow-up messages of appreciation for remembering to use an app, have little effect on habits to use the app (Stawarz et al., 2015),

In summary, social media habits form due to the various rewards that consumers receive on a site. Site rewards capitalize on consumers' existing emotional and social needs by presenting a distilled version of social experiences. Each site is designed with rewards that attract certain types of users. In addition, the experience of rewards on social media is enhanced due to the uncertainty inherent in scrolled presentations of content, algorithmically curated scrolls that highlight content of interest, experiences of social comparison, visible popularity, reciprocity norms for mutual reading and following, and reward immediacy. Once consumers decide to use a platform, the systems within it are constantly adjusting to heighten its appeal and make it more rewarding-with the goal of keeping existing users coming back.

\section{3 | Friction reduces rewards}

Barriers and delays create friction in using social media sites and reduce consumers' experience of rewards. For example, slowdowns and access problems with a financial app increased users' frustration and hindered repeated use (Ash et al., 2018). Furthermore, tolerable wait times to download information on the web seem to average around $2 \mathrm{~s}$ before users abandoned a link (Nah, 2004). More generally, longer wait times and greater numbers of clicks required to access a site decreased the quality of user experience (Baraković $\&$ Skorin-Kapov, 2015). In this way, the friction experienced when using a social media site creates unfavorable intentions to use a site and hinders repeated use (see Figure 2).

Countering the tendency for friction to decrease rewarding experiences, insufficient friction on social media can raise concerns about privacy (Alter, 2017; Aral, 2020; Kosslyn, 2018). For example,
Facebook introduced in 2011 frictionless sharing, in which user updates were displayed immediately into newsfeeds. This feature was termed creepy by some users, created concerns over privacy, and it has since been abandoned (Southern, 2017). Social media sites have also added friction at times in order to slow users. For example, during the final weeks of the 2020 U.S. presidential election, Twitter restructured retweeting of others' posts in an apparent attempt to slow the spread of misinformation (Hatmaker, 2020; Vincent, 2020). Specifically, the default quick-retweet button was changed into a quote tweet that prompted users to comment before reposting, even asking users "do you want to read this article before tweeting it?" Thus, social media sites reduce friction of delays and clicks in order to heighten users' experience and promote repetition, but at times easy sharing can create problems for users and for the sites themselves.

\subsection{Motivation fades as habits form}

As consumers respond to rewards, develop more favorable intentions to use a site, and repeatedly act on these intentions, they begin to form habit associations between site use behaviors and cues in the performance context. Cues become important in part because of their past association with rewards. Research has shown that stimuli that were rewarding in the past attract attention even when irrelevant to a current task (Rusz et al., 2020). For example, when colored shapes in an online task had previously been associated with rewards, the shapes continued to attract participants' attention despite being irrelevant to what they were currently doing (Anderson, 2016). When applied to the rewards obtained through social media, these findings suggest that the sight of a social media app's log-in button or its bookmark in a browser can attract consumers' attention and distract them from other tasks. In this way, past rewards can influence which cues are important when using a site.

As we explained in the introduction to this article, once habits strengthen and context-response associations form, the responses of logging in and using a site are automatically brought to mind by perception of cues in the performance context. Thus, as shown in Figure 3 , media use habits are directly activated when consumers perceive the relevant context cues. 
One implication of the direct activation of site use responses by cues is that intentions to use a site become less influential guides to action once habits have formed. That is, consumers repeat habits when cued, with only limited input from their intentions. This direct activation of habits was illustrated in research on another media form, TV news. After measuring college students' habits to watch TV news and their intentions to watch for the following week, Ji and Wood (2007) had participants report each day whether they had in fact watched the news. As shown in Figure 4, participants with stronger habits to watch the news in a particular physical location (e.g., bedroom) continued to watch a relatively constant amount regardless of their intentions. In this way, strong TV habits directly perpetuated the amount watched. Also evident in Figure 4, participants with weaker habits carried out their TVwatching intentions, whether it was to watch a lot or a little during the week of the study.

Habit persistence despite intentions has been demonstrated widely across habit research. Although we know of no demonstrations specifically with social network sites, this pattern has been found in research on technology and information systems habits. That is, habit strength acted as a boundary condition beyond which intentions were less predictive of technology-use behavior (Limayem \& Cheung, 2008; Limayem et al., 2007). Thus, as consumers developed stronger habits to use a technology, their future use was predicted less effectively by their intentions to use it.

\section{4 | PERFORMING HABITS: CUES THAT ACTIVATE CONTINUED USE OF SOCIAL MEDIA}

A variety of context cues might become tied to social media use and thereby come to trigger it automatically. In this section, we consider how each of the various types of cues mentioned in Figure 3 can activate habit performance, including moods and

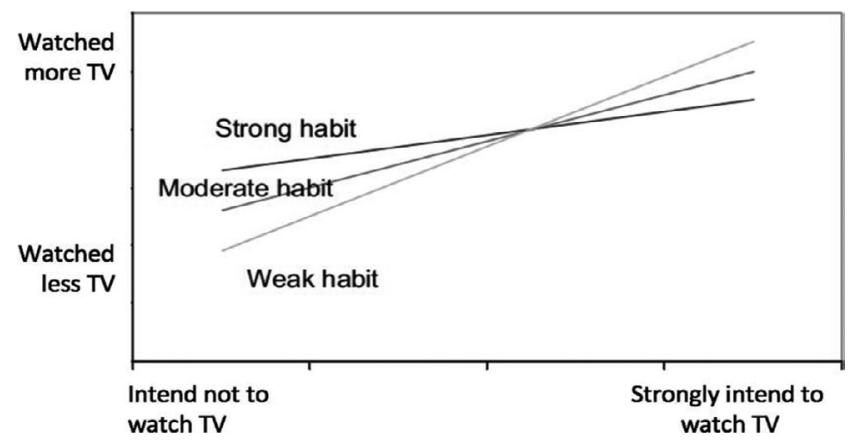

FIGURE 4 Frequency of Watching TV News as A Function of Habit Strength and Watching Intentions. Note. Frequency of watching TV news during a week-long study (assessed through reports each night) as a function of habit strength to watch TV news in a particular location and intention to watch during that week (from Ji \& Wood, 2007) emotions, within-site design features, supporting technology, and broader activities.

\section{1 | Mood cues}

The moods and emotions that are associated with social media use potentially act as triggers for subsequent use. For example, college students who felt less certain how to complete a school task procrastinated more by checking Facebook (Meier et al., 2016). Suggesting that habits were involved, this effect was especially evident for students who used Facebook automatically out of habit. Also, in an experience-sampling study of daily smartphone use, boredom was the biggest predictor of phone use, with phones often used to access social media (Smith, 2015). Being around people to avoid was also associated with smartphones and thus social media use in this study. In other research, stress or anxiety, and social stress in particular, were associated with more frequent smartphone use among more habitual users (Deursen et al., 2015). Thus, certain emotions appear to automatically trigger use of smartphones and social media.

\section{2 | Design feature cues}

Site designs also provide notifications that can become cues automatically activating use. Push notifications, for example, may be important in habit formation. Such notofications increased the frequency of visits to an app for habitual users in comparison with (a) habitual users without such notifications and (b) less habitual users (Kim, 2014). Many social media apps also have unique sounds that accompany their notifications, and these can become distinct cues to trigger use. Along with habit formation, design features may also implicate classical conditioning, in which consumers learn through repetition to associate performance rewards with an auditory or visual cue, and this cue comes to trigger behavior to attain that reward (Schonberg et al., 2014).

Site design features can also act as technological nudges that guide the formation of specific use habits. For example, unlike video games in which ethical design prescribes splitting the game into chapters that guide players to natural stopping points, many social media sites have removed stopping cues (Alter, 2017). Facebook established an endless, aggregated newsfeed shortly after Twitter did so, and added autoplay functions to all videos on the site by December 2013, both of which effectively push users to continue to consume content (Linshi, 2015). Twitter, TikTok, Facebook, and Tumblr also provide bottomless feeds without natural endpoints. This design feature encourages users to keep browsing, scrolling, and spending time on the sites and promotes habits of long use times. The decrease in friction through the removal of stopping cues, or natural endpoints to limit media use, may be a major key to social media's global success (Alter, 2017). 
Features of site design also explain why some apps fail to retain consumers. In an experiment testing the effectiveness of app features over a 4-week period (Stawarz et al., 2015), event-based cues to respond to the app (e.g., after lunch) were more effective at building automaticity and habitual repetition than use reminders. Although reminders initially increased participants' use, they did not build automaticity but instead appeared to increase participants' thought about their responses. Thus, design cues that spur responding over thinking may be more effective at promoting habit formation.

\section{3 | Technology cues}

The technology consumers use to access social media, including computers, laptops, tablets, and smartphones, provide another context cue to social media use. In fact, social media use took off simultaneously with the popularity of smartphones. Smartphone technology reduced friction, as social media became accessible wherever a smartphone could be used. In 2019, both technologies reached roughly $80 \%$ of U.S. households (Ortiz-Ospina, 2019).

Suggesting that smartphones can be a cue to social network habits, a month-long study of forming habits to use a new sports app revealed that pre-existing smartphone habits promoted the formation of app-use habits (Schnauber-Stockmann \& Naab, 2019). In this way, students with stronger habits to use their smartphones were able to stack a new habit onto an old one and take advantage of the existing automaticity (see Labrecque et al., 2017). Thus, consumer habits related to technological pathways, such as laptops, tablets, and smartphones, facilitate forming habits to use online sites.

One prominent example of stacking onto existing habits comes from Snapchat users. When Instagram copied Snapchat's in-the-moment video-sharing feature, stories, Snapchat users were easily able to stack their habits onto use of the Instagram platform. Ultimately, the stories function had more users on Instagram (400 Million daily active users) than Snapchat (186 Million daily active users, Mediakix, 2019). Users may have been prompted to switch away from Snapchat by multiple site redesigns, as suggested by anecdotal complaints from former power-users like Kylie Jenner (Mediakix, 2019). Such redesigns are especially problematic for habitual users, as we show in the next section of the article (see "Platform discontinuity effects"). Thus, Snapchat's redesigns, paired with users' stacking onto Instagram, likely contributed to that site's recent downturn.

\section{4 | Location and activity cues}

Finally, places, times of day, and activities can serve as cues triggering media use. For example, drivers who reported frequently reading and sending text messages while on the road also reported engaging in these behaviors in more automatic and habitual ways (Bayer \& Campbell, 2012). This was true even after controlling for drivers' awareness, control, and intentions related to these actions. Thus, the mere act of driving appeared to function as a trigger for text messaging habits Consumers also use certain social media sites in particular locations. In a survey of roughly 5,000 users of five major social media sites, the app used most when hanging out with friends was Snapchat, whereas Instagram, Facebook, and YouTube were used more at home, while unable to sleep, and to pass time while waiting; Twitter was most frequently used while commuting (Snap \& Inc., 2019). For habitual users, these places, times, and daily events may all become cues triggering use (e.g., automatically opening Twitter while sitting on the bus or subway).

In summary, social media platforms provide cues that create stable contexts and facilitate habit formation. Repetition in these contexts is an important part of building habit memory pathways. Media sites capitalize on consumers' moods, within-site design cues, supporting technology cues, and broader location or activity cues, each of which can eventually become a trigger for social media habits. Media platforms also nudge extended-use habits through endless scrolls without cues to stop. Additionally, social media has taken advantage of stacking by building on smartphone cues and by individual sites borrowing cues from other sites. Repeated use of social media became easier as mobile access reduced friction. Once consumers have formed social media habits, these cues activate use with limited input from intentions (see Figure 3). In this way, cues become the primary drivers of repeated social media use.

In the next section of the article, we consider how existing social media habits influence consumers' attempts to quit or reduce their use. As we explain, habits persist by thwarting consumers' intentions to change as well as their actual attempts to limit use.

\section{5 | HABITS AND QUITTING: HABITS PERPETUATE USE}

Quitting social media, or even stopping using a particular website, is challenging to the extent that consumers have formed strong use habits. Nonetheless, consumers may decide for a variety of reasons to reduce or quit using a social networking site. Such decisions are termed discontinuance intentions. For example, in a study of Facebook users, the stress of keeping up with the technology and feelings of tiredness and being drained from using it were associated with intentions to reduce future use or to deactivate one's account (Luqman et al., 2017). Discontinuance intentions for social media sites also are tied to feelings of regret and being overloaded by contacts or features on a site (e.g., Fu et al., 2020; Wang et al., 2020).

Discontinuance intentions represent an initial start to reducing social media use. Yet, habits to use social media hinder even making this decision, as consumers weigh the financial, social, and psychological costs of reducing commitment to an incumbent media site and potentially switching to a new one (Polites \& Karahanna, 2012). Using a new site, for example, requires not only learning its features but also building a new profile and informing 
existing contacts. When such transition costs outweigh the benefits, people experience cognitive lock-in (Murray \& Häubl, 2007) and have an explicit psychological commitment to the incumbent site due to the perceived sunk costs (Polites \& Karahanna, 2012). The result is inertia, which leads to decreased perceptions of the ease of use and relative advantages of the new site, and ultimately impedes discontinuance intentions (Wang et al., 2020). In addition, habits influence intentions in less rational ways. For example, the feeling of familiarity with a site is likely to increase users' liking for it and feelings of safety and privacy when using it (Avni-Babad, 2011).

Although habits hinder forming discontinuance intentions, some consumers intend to quit despite their strong habits. However, habits impede even this second step in the quitting process. The slow-to-change memory trace of habits is not responsive to decisions to change, and habitual responses continue to be activated in memory regardless of consumers' intentions. As we explained above, consumers continue to act on habit despite conflicting intentions, attitudes, and social norms (Itzchakov et al., 2018; Ji \& Wood, 2007; Mazar et al., 2020). Thus, despite having formed discontinuance intentions, habitual consumers are likely to be cued by everyday contexts, their phones, and the platform itself to continue using social media.

Evidence of the persistence of habits despite consumers' best intentions comes from research on privacy risks on social media. College students who habitually used Facebook proved especially vulnerable to phishing attacks, or deceptive messages designed to steal users' identity and monetary information. That is, habitual users clicked the "confirm request" icon seemingly automatically and often accepted an initial friend request from a phony profile. Then, 2 weeks later, they also were likely to provide personal information to a request from the same fake profile on the site (Vishwanath, 2015). In fact, habitual users were caught more often by this phishing attempt than less habitual ones. It might seem surprising that habits increased vulnerability to deception, given that frequent users' experience with social media should arm them against privacy risks. However, even habitual users who were highly concerned about privacy acted automatically and fell victim to providing personal information to the phishing request (Vishwanath, 2015). Social media habits persist by automating responses to site cues as well as reducing suspicions about the perceived risk of a phishing message (Parker \& Flowerday, 2020; Vishwanath et al., 2018).

This persistence of social media habits likely contributes to the generational differences in social media site use. Facebook, which was one of the first social media sites to become generally available as early as 2006 , is used relatively evenly by all age groups, with $79 \%$ of people aged $18-29$ ever using it, and $68 \%$ of people aged 50-64 (Perrin \& Anderson, 2019). In contrast, newer websites like Snapchat and Instagram, which became available slightly later, around 2011, have younger user profiles, with $62 \% / 67 \%$ of 18 - to 29 -year-olds using Snapchat/Instagram but only $9 \% / 23 \%$ of 50- to 64-year-olds. Of course, many differences between these websites may account for these effects, including that younger users may be attracted more to image- and video-based media. However, a likely contributing factor is that consumers developed habits to use particular sites when they initially became available and then persisted in habit performance despite the introduction of newer sites.

In summary, more habitual users of social media are less likely to form discontinuance intentions and, once formed, are less able to carry them out through quitting or reducing social media use. However, habits can be changed when consumers use specific self-control strategies or when context cues shift.

\section{1 | Controlling social media habits}

Consumers could use a variety of self-control strategies to limit their use of social media. In exerting such control, college students most often modified their access to social media sites, such as muting a phone or turning off data and wi-fi, or they engaged in straightforward self-control by forcing themselves to focus on other tasks and to ignore social media (Brevers \& Turel, 2019). Even when using such strategies, however, students with stronger social media use habits were less successful at controlling excessive use than those with weaker habits (Brevers \& Turel, 2019).

Straightforward self-control through vigilant monitoring, or thinking, "don't do it," and closely monitoring behavior was, in other research, the most successful strategy for curbing habits that consumers wanted to inhibit in everyday life (Quinn et al., 2010). Almost $10 \%$ of instances in which participants reported trying not to do something involved stopping excessive media use such as online chatting, connecting with friends, and watching screens-it was the fourth most common type of response that participants tried to control. Nonetheless, participants using vigilant monitoring were able to inhibit acting on habit.

Despite its short-term success, active self-control is more difficult to maintain than altering the cues that trigger media habits, such as putting a cell phone on mute (Brevers \& Turel, 2019). Furthermore, the strategy of changing cues should especially curb strongly habitual use, given that habits are activated directly by such cues. In the next section, we report a novel test of the power of disrupting cues as a means to reduce social media use.

\section{2 | Platform discontinuity effects: a case study in the power of cues}

To test the power of context cues to control media use habits, we tested platform effects, or discontinuities in user behavior that result from changes in social media platform design (Malik \& Pfeffer, 2016). Such changes are implemented by social media sites in order to enhance user experience and increase use. Although this might be the effect for occasional or beginning users, we anticipated that changes in relevant cues would disrupt the automaticity driving high 
frequency, habitual users, and thus might impede their use. Note that this prediction is consistent with research on habit discontinuity, in that immediately after relocating house or starting at a new job or university, consumers' habits are disrupted by the change in cues in their everyday contexts (Verpanken et al., 2019).

Discontinuity effects were modeled in an online experiment with changes in the format of alerts and other dialog selection designs common to social media sites (Garaialde et al., 2020). After extensive experience responding to an original design format, participants responded quickly and accurately. However, once the design changed, responses slowed and became less accurate, suggesting a disruption in automatic responding.

To test discontinuity effects in the ongoing use of social media, we conducted a reanalysis of existing Facebook data on the development of user-to-user interaction, specifically users' wall postings (for the original data, see Vishwanath et al., 2009 ). Our analysis evaluated a previously unexplored feature of these data: How wall posting rates were influenced by a platform change designed to allow others to "more easily view wall posts through friend feeds." Specifically, we compared the rate of Facebook wall posts, as reflected in the latency between posts, during the month before the platform change (June 20, 2008, to July 20, 2008), with the rate during the month after the change (July 20, 2008, to August 20, 2008). We also estimated habit strength from posting frequency for the 6 months prior to the start of assessment (i.e., January 20, 2008, to June 20, 2008).

Most importantly, our predicted interaction between habit strength and the change in platform design was significant in predicting log latency, or time between posts (see Table 1), $\beta=0.002$, $d f=49,430, p<.001$. Figure 5 illustrates the interaction graphically. The solid line and shaded area depict the estimated effect and confidence interval for the association between habit strength and latency prior to the platform change. The dashed line depicts this association after the platform change. As can be seen, for the least frequent posters, the platform change reduced post latency, encouraging them to post more rapidly than before the change. However, more frequent, habitual posters were disrupted by the change and posted with greater latency after the change than before. Specifically, log latency between posts increased after the change for all users who had posted greater than 95 times in the prior 6 months. For example, a heavy user with 500 posts over the prior 6 months increased average post latency by about $6.5 \mathrm{~s}$. Thus, habitual posters responded to the change in platform by posting more slowly, yielding a decline in their posting rate, presumably because the change disrupted the automaticity of habitual posting.

Two incidental effects also emerged from the analysis (see Table 1). First, log latency was negatively associated with habit strength, reflecting shorter latency between posts among more frequent users. Thus, users with stronger habits before the change continued to post more often during the 2 month of the study. This effect reflects habit persistence. Second, the change in platform design had the intended effect, with the mean log latency between posts significantly lower after the change than before it, reflecting an increase in the rate of posting with the change. Thus, the design change was an overall improvement to Facebook, facilitating more frequent posting.

In summary, our test of platform changes revealed the vulnerability of strongly habitual users to changes in platform design. Although this change was broadly effective in boosting consumers' overall wall posting, this overall success hides an important story illuminated by a habit-based analysis: If context cues are disrupted, then habitual users can no longer rely on them to activate use. In general, cue disruptions force people to respond more thoughtfully and rely on their intentions to act, with the result that they continue behaviors they intend to perform and discontinue ones they do not (Wood et al., 2005).

\section{3 | Overuse of social media}

Habitual social media use is a behavioral response system that, when followed excessively, could be classified as an addiction. Although not formally recognized as a psychiatric or psychological disorder (e.g., in the Diagnostic and Statistical Manual of Mental Disorders-5), addiction to social media is increasingly a concern in the popular

\begin{tabular}{|lllll|} 
& df & $\boldsymbol{\beta}$ & $\boldsymbol{p}$ & $95 \% \mathrm{Cl}$ \\
\hline Intercept & 15,390 & 12.91 & $<.001$ & $12.86,12.97$ \\
\hline $\begin{array}{l}\text { Number of past posts (habit } \\
\text { strength) }\end{array}$ & 4,937 & -0.02 & $<.001$ & $-0.02,-0.01$ \\
\hline $\begin{array}{l}\text { Timing of change }(0=\text { before, } \\
1=\text { after) }\end{array}$ & 52,640 & -0.19 & $<.001$ & $-0.24,-0.13$ \\
\hline $\begin{array}{l}\text { Interaction between number of } \\
\text { prior posts and timing of change }\end{array}$ & 49,430 & 0.002 & $<.001$ & $0.001,0.003$ \\
\hline
\end{tabular}

TABLE 1 Results of multilevel regression model predicting between-post Facebook latency as a function of timing of a Facebook platform change and past posting habit strength

Note: Estimates are the non-standardized coefficients $(\beta)$ of the terms in the multilevel model in R. Between-post latency (log seconds) is a participant-level variable, and timing of the platform change is a group-level variable. Degrees of freedom were calculated using the Satterthwaite method for multilevel models. $N=9,469$ Facebook users and 53,208 wall posts from the New Orleans area between June 20,2008, and August 20, 2008. Data originally appeared in Vishwanath et al. (2009), and Alan Mislove graciously shared them for our analysis (September 9 , 2020). 
FIGURE 5 Plot of Latency Between Facebook Posts As A Function of the Timing of A Platform Change and Past Posting Habit Strength. Note. The criterion is posting latency (log seconds), reflecting the amount of time between users' Facebook posts, and the predictors are numbers of past posts (reflecting habit strength) and timing of the Facebook platform change

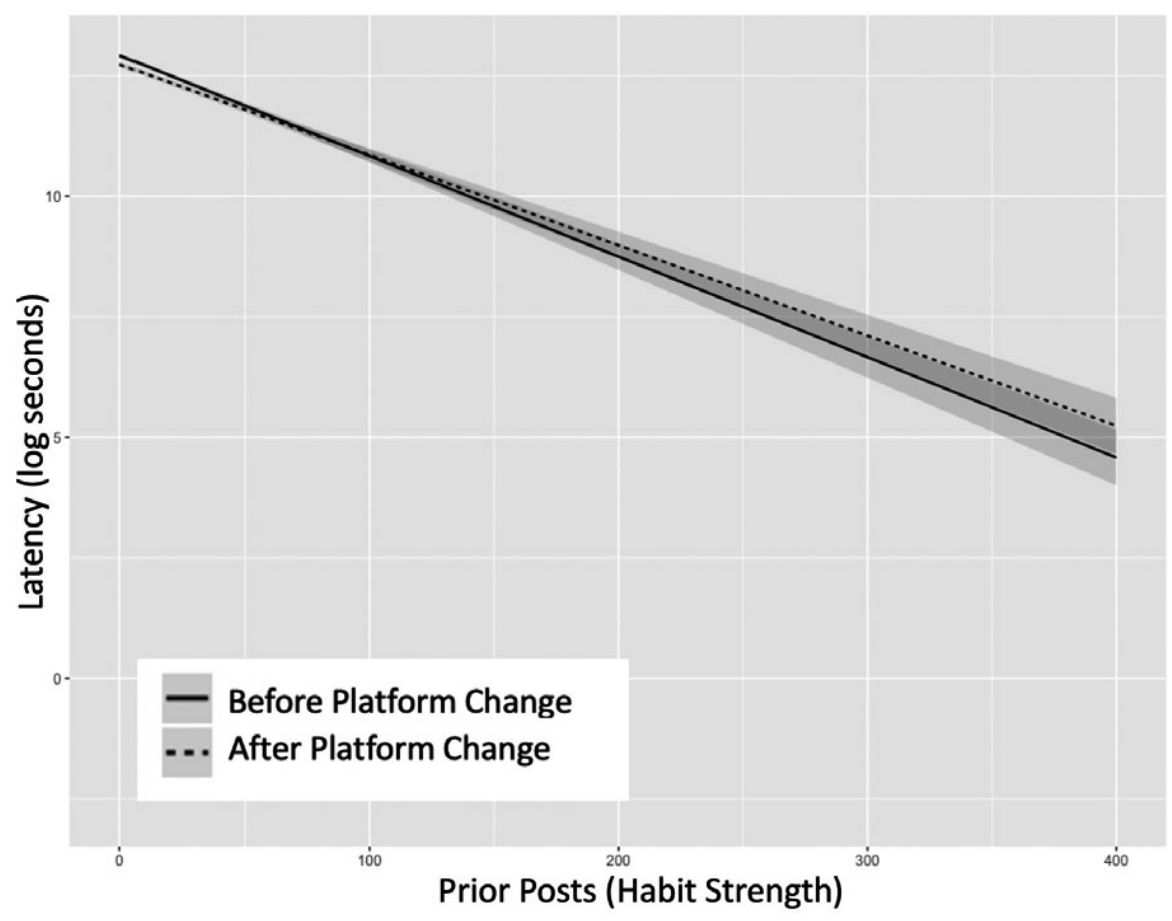

press and in research. Like other addictions, excessive social media use is often considered a maladaptive state of psychological dependency (e.g., Turel \& Serenko, 2012). Overuse of social media can be a self-regulatory failure reflected in an obsessive pattern of seeking and using social media that infringes on normal functioning (Alter, 2017; LaRose et al., 2010; Turel \& Serenko, 2012). These ideas are captured in the Facebook Addiction Scale, which assesses six components of social media addiction: salience in dominating thinking and behavior, use in order to improve or change mood, increase in tolerance to effects, conflict with other activities, unpleasant feelings on limiting use, and relapse after successful episodes of control (Andreassen et al., 2012).

Researchers have sometimes falsely equated habitual use with addiction. For example, in an evaluation of the basis of Facebook addiction, Ryan et al.'s (2014) review concluded that addictive use is tied to the experience of such gratifications as maintaining relationships and passing time. However, these rewards also motivate occasional users of social media and lead to the formation of use habits; they are not necessarily linked to addiction. Instead, in a more informed analysis, Brevers and Turel (2019) noted that stronger habits to use social media are moderately correlated with but not identical to the severity of addiction symptoms. In their analysis, habits can become problematic and lead to addiction, but the automaticity in habit is only one component of the maladaptive overuse of social media.

In summary, social media use habits make it difficult for consumers to quit or reduce use. In part, this effect is rational, as habitual users may judge that the costs of switching outweigh any benefits. Thus, habitual users are less likely to form discontinuance intentions. In addition, existing habits directly impede attempts to reduce use, as recurring context cues activate thoughts of logging on and scrolling feeds. Nonetheless, social media users can effectively control their habits by vigilantly exerting self-control. However, the effort required by this strategy is difficult to maintain, and users may find it easier to control the cues that activate media use. Suggesting the effectiveness of controlling cues, we found in a novel test that changes in Facebook's posting platform reduced the posting rate of strongly habitual users. Apparently, the changes disrupted frequent users' automaticity. Finally, we concluded by noting that habitual media use is not necessarily an addiction. Habitual use is only moderately correlated with reports of problematic or excessive use, consistent with media use habits promoting both desired and undesired outcomes for users.

\section{6 | THE NEXT GENERATION OF SOCIAL MEDIA}

Our analysis of the psychology behind social media habit formation, performance, and change provides a lens through which we can envision the future of social media use. Habits, as a backward-looking memory system focused on past contexts, responses, and rewards, might seem an unlikely framework for making predictions about this future. However, the habit learning system has been central to the past successes of social media, and we predict that future innovations will succeed to the extent that they similarly engage consumer habits.

As we have shown in this article, the central features that contribute to consumers' habitual use of media sites include structuring rewards to motivate initial and occasional use as well as capitalizing on context cues to encourage continued use. Additional contributors include sites streamlining features to make use more rewarding and 
easier to repeat, enabling consumers stacking social media use onto existing habits, and avoiding pitfalls of changing platform design. By creating habit-forming sites in these ways, social media can foster the habitual use that is central to success. Understanding of consumer habits thus augments more standard analyses of new product success, which typically reference the broader national culture, a firm's market orientation, or its personnel resources (Evanschitzky et al., 2012).

To illustrate habit-based insights into product success, we first consider how consumers reacted to two older technologies related to social media, camera phones and blogging sites. In doing so, we speculate about the role of habit-forming features in driving consumer reactions when these products were first introduced.

A cell phone with picture capability, for example, was a really new product in the early 00s (Alexander et al., 2008). Its subsequent success can be understood in terms of its ability to form consumer habits. Taking cellphone pictures offered consumers new rewards by producing images that could be seen and shared immediately. Picture quality improved rapidly to make the photographs themselves more rewarding. The mobile platform put low friction on repeated use in everyday contexts, and taking photographs could be stacked onto the automaticity of existing phone use habits. Cameras ultimately became a phone staple and, in turn, likely promoted consumers' use of photo-centered social media platforms like Instagram and Snapchat.

Blogging was another really new product in the late 00s, but was less successful, being largely supplanted by social media sites such as Twitter's micro-blogging. We speculate that, compared with older blogging sites, social media provides more immediate, lower-friction rewards from larger numbers of users, encourages repeated use by leveraging reciprocity norms among users, and presents content in centralized scrolls that increase the experience of intermittent, uncertain rewards. Social media has also assumed precedence as a single-stop site for multiple rewards, including posting, reading news, and checking sports scores. Most likely due to its lesser rewards, blogging has become a niche activity with more limited market reach.

\section{1 | Past social media successes and failures}

We can also illustrate the usefulness of a habit analysis by applying it to understand how currently popular social media sites supplanted earlier ones. Again, we are speculating from the research findings we already discussed in order to identify the winners and losers in the social media landscape.

Facebook, for example, had the advantage of a relatively fixed, stable platform for users compared with predecessors, Myspace and Xanga, and provided more rewards embedded in the platform than contenders, Friendster and SixDegrees. In another innovation, Twitter's capitalization on news altered the social landscape by making the platform integral to consuming news media. Twitter's design also streamlined postings and reduced friction through single-button sharing and short-form content. These features arguably generated the modern concept of virality and helped define it through attention-grabbing language (Brady et al., 2020). Further contributing to Twitter's success is the potential for information to go viral-an aspirational reward for posters and an unexpected reward for readers.

More recently, Facebook acquired Instagram along with the challenge of adding advertisements to turn it into a revenue generator (a.k.a., growth-focused design, Eyal, 2014). However, adding obvious advertisements can alter context cues and dilute content-based rewards during scrolling, thereby impacting both habitual and non-habitual users. In illustration, Myspace's poorly integrated advertising (banner and side-bar ads, autoplay pop-up videos) disrupted cues and rewards and apparently prompted the exodus of both new and core users, with Facebook eventually supplanting it as the leading platform (Torkjazi et al., 2009). Accordingly, instead of intrusive advertising, Facebook is using native ads (a pay-for-reach model in which influencers and brands pay to put content in front of consumers) embedded in the existing platform, so as to leave scrolling intact.

Other apps, like TikTok, have also successfully capitalized on design features that form user habits. TikTok adapted many of the successful rewards and context cues from Twitter's now-defunct Vine short-video app, while adding their own. Despite being rewarding, easily accessed, and at times wildly popular, Vine did not generate sufficient revenue to evolve beyond its niche users (Newton, 2016). After Vine shuttered, the better-funded and managed TikTok seized the opportunity. TikTok has been successful both because it introduced a highly rewarding and easily repeatable short-form video-sharing platform to a new generation of users and because it had an older generation of users already primed by Vine to enjoy it.

\subsection{The future of social media}

Principles of habit formation and performance explain not only the success of existing social media sites but also that of future ones. This idea has already gained some popular traction (Eyal, 2014), and designers of social media sites acknowledge the importance of components of habit formation such as providing rewards, enabling frictionless repetition, and creating cues to trigger use (Rhodes \& Orlowski, 2020). Although a habit-centered terminology is not widely used at present, we anticipate that sites will increasingly acknowledge the value of creating a strongly habitual user group.

Hardware developments should continue to be important for social media, given the research we mentioned above that app use can be stacked onto already-developed smartphone habits (SchnauberStockmann \& Naab, 2019). Social media sites will want to continue to capitalize on newly emerging phone capabilities to tailor their own 
sign in, use, and notification systems. Other technological advances that could benefit social media involve extended reality, including augmented and virtual reality, and 5G.

Virtual reality has been less successful thus far than social apps as an investment for social media (e.g., Oculus by Facebook). Current virtual reality technologies are comparable to homebased, console videogames (e.g., Xbox) in being cumbersome to use outside of the home and associated with only a limited set of cues. This friction hinders user rewards and repetition. Recognizing this, modern video game consoles have started to integrate more portable features (e.g., Nintendo Switch), and virtual reality might similarly be developed for repeated use in everyday contexts (despite pitfalls of Google Glass). In contrast, augmented reality is already somewhat streamlined, yielding greater potential for easily repeated use, habit formation, and stacking onto consumers' existing habits. For example, augmented reality platforms are already using cellphone cameras to place video game figures in real-world environments (e.g., Pokemon Go).

Perhaps most exciting is the potential for augmented reality and virtual reality to provide new frontiers for social interaction, especially when in-person contact is difficult (e.g., the COVID-19 pandemic). Social rewards that are part of an augmented reality platform could build on the rewards already provided by today's social media sites by enabling users to create experiences to share with others.

Broader availability of extended reality might become possible with high-grade $5 \mathrm{G}$ internet technology that offers near-instant sharing, loading, and access to content, and that thereby rewards and facilitates repeated use. The new technological developments associated with $5 \mathrm{G}$ potentially combine augmented and virtual reality with more complex and interesting content along with improved portability that enables frictionless repetition in everyday settings. For example, a new social app could achieve success on a 5G network by streamlining users' creation and sharing of augmented-reality-integrated videos with easy-to-design or cut-and-paste figures beyond GIFs. Additional potential can be found in 5G-enabled collaborations among video-sharing users, such as creating virtual reality backgrounds for video content. Regardless of the specific innovations, we believe that sites' future success hangs on surpassing competitors by better capitalizing on the processes of building and retaining consumer habits.

\section{SUMMARY AND CONCLUSION}

Social media sites depend closely on consumers' habits. We started this article with evidence that daily, habitual use of social media platforms is central to their market success. Throughout the remainder of the article, we explained how social media sites have effectively formed and activated consumer use habits. We drew on the psychological dynamics behind habit formation and performance to analyze the rewards that social media sites provide to attract initial users and encourage repeated use. We discussed how reducing friction provides additional rewards. We also identified social media context cues that not only activate existing use habits but also nudge users to continue. We validated our analysis with a novel test showing that a Facebook platform redesign that increased engagement among casual users also threatened the automaticity of habitual users. Thus, social media companies may incur losses or shifts in their user base with even the best designed platform changes. Finally, we drew on habit learning to make predictions about the future of social media sites, highlighting how new products can gain traction in the marketplace by creating user habits.

We also challenged the idea that habitual use is the same as addiction. This is not to say, however, that social media products are beneficial for individuals or for society more broadly. On the individual side, frequent or passive users may benefit from cessation, as a 1-week break from Facebook increased these users' life satisfaction and positive emotions (Tromholt, 2016). However, other research has found that short periods of abstinence have no effect (e.g., Agadullina et al., 2020; Hall et al., 2019) or have negative effects such as increased loneliness and decreased life satisfaction (Vally \& D'Souza, 2019; Vanman et al., 2018). The habit-forming nature of social media may thus, like most habits, yield a range of costs and benefits.

On the societal side, popular documentaries like The Social Dilemma and The Great Hack reflect the public's deep concerns about the effects of social media technologies. The Cambridge Analytica scandal, in which Facebook user data were adapted to target potential voters with disinformation in the 2016 U.S. election, is sometimes cited as evidence of negative impact and challenges to consumer data and privacy. In addition, features that promote repeated behavior and drive consumers toward habitual or addictive use have raised concerns among the scientific community, casual observers, and even former designers of the technologies (Rhodes \& Orlowski, 2020). Paired with evidence of misinformation, algorithmic bias, and wider societal impacts, these have led to increasing proposals of government regulation of social networks (Aral, 2020; Noble, 2018). These reputational risks may discourage non-habitual users, but habitual users are likely to persist. However, if regulations force changes in the sites themselves, then unease about social media platforms may be enough to shake habitual users loose. Thus, public support for social media is entwined with threats to platforms' reputation and with user habits.

Finally, our analysis of social media success and consumer habits has broader implications for future research on consumer behavior. For marketers and professionals, this article identifies a psychological process, habit formation, that augments more common analyses of new product success (see Evanschitzky et al., 2012). Given that consumer habits are the fuel that drives repeated use in the online marketplace, the psychology of habit can usefully guide development of other products that rely on repeated use. By rewarding new and occasional consumers, reducing friction to promote repetition, and creating context cues to automatically activate use, products can make themselves integral to consumers' daily life. To date, social media platforms are one of the most successful products to leverage these strategies. 


\section{ACKNOWLEDGMENTS}

The authors thank Alan Mislove for graciously sharing the data file on Facebook design change, along with Julie Cho, Carol Iskiwitch, Drew Kogon, and Asaf Mazar for their helpful comments on an earlier version of this manuscript. Data for the analyses we report in the article are available at https://osf.io/d8xys/.

\section{ORCID}

Ian A. Anderson (iD https://orcid.org/0000-0002-3362-4536

Wendy Wood iD https://orcid.org/0000-0002-6117-558X

\section{REFERENCES}

Agadullina Elena R., Lovakov Andrey, Kiselnikova Natalia V. (2020). Does quitting social networks change feelings of loneliness among freshmen? An experimental study. Journal of Applied Research in Higher Education, http://dx.doi.org/10.1108/jarhe-11-2019-0283.

Alexander, D. L., Lynch, J. G., \& Wang, Q. (2008). As time goes by: Do cold feet follow warm intentions for really new versus incrementally new products? Journal of Marketing Research, 45(3), 307-319. https://doi. org/10.1509/jmkr.45.3.307

Alhabash, S., \& Ma, M. (2017). A tale of four platforms: Motivations and uses of Facebook, Twitter, Instagram, and Snapchat among college students. Social Media and Society, 3(1), 1-13. https://doi. org/10.1177/2056305117691544

Alter, A. (2017). Irresistible: The rise of addictive technology and the business of keeping us hooked. Penguin.

Amodio, D. M., \& Ratner, K.G. (2011). A memory systems model of implicit social cognition. Current Directions in Psychological Science, 20(3), 143-148.

Anderson, B. A. (2016). The attention habit: How reward learning shapes attentional selection. Annals of the New York Academy of Sciences, 1369(1), 24-39. https://doi.org/10.1111/nyas.12957

Anderson, I., \& Wood, W. (2020). Social media habits: When others' reactions don't matter. Unpublished manuscript. University of Southern California, Los Angeles, CA

Andreassen, C. S., Torsheim, T., Brunborg, G. S., \& Pallesen, S. (2012). Development of a Facebook addiction scale. Psychological Reports, 110(2),501-517.https://doi.org/10.2466/02.09.18.PR0.110.2.501-517

Aral, S. (2020). The hype machine: How social media disrupts our elections, our economy, and our health-and how we must adapt. Currency.

Archambault, A., \& Grudin, J. (2012). A longitudinal study of Facebook, LinkedIn, \& Twitter use. In Proceedings of the SIGCHI Conference on Human Factors in Computing Systems, USA, pp. 2741-2750. https:// doi.org/10.1145/2207676.2208671

Ash, J., Anderson, B., Gordon, R., \& Langley, P. (2018). Digital interface design and power: Friction, threshold, transition. Environment and Planning D: Society and Space, 36(6), 1136-1153. https://doi. org/10.1177/0263775818767426

AudienceProject. (2019). Leading Facebook usage reasons according to users in the United States as of 3rd quarter 2019 [Graph]. Statista. Retrieved September 16, 2020, from https://www-statista-com. libproxy1.usc.edu/statistics/972892/reasons-being-on-faceb ook-usa/

Avni-Babad, D. (2011). Routine and feelings of safety, confidence, and well-being. British Journal of Psychology, 102(2), 223-244. https://doi. org/10.1348/000712610X513617

Baraković, S., \& Skorin-Kapov, L. (2015). Multidimensional modelling of quality of experience for mobile web browsing. Computers in Human Behavior, 50, 314-332. https://doi.org/10.1016/j. chb.2015.03.071

Bayer, J. B., \& Campbell, S. W. (2012). Texting while driving on automatic: Considering the frequency-independent side of habit. Computers in Human Behavior, 28(6), 2083-2090. https://doi.org/10.1016/j. chb.2012.06.012

Bayer, J. B., \& LaRose, R. (2018). Technology habits: Progress, problems, and prospects. In B. Verplanken (Ed.), The psychology of habit: Theory, mechanisms, change, and contexts (pp. 111-130). Springer. https://doi. org/10.1007/978-3-319-97529-0_7

Biyani, G. (2013). Chamath Palihapitiya-how we put Facebook on the path to 1 billion users [Video]. YouTube. Retrieved October 20, 2020, from https://www.youtube.com/watch?v=ralUQP71SBU\&featu re $=$ youtu.be\&t $=21 \mathrm{~m} 5 \mathrm{~s}$

Brady, W. J., Gantman, A. P., \& Van Bavel, J. J. (2020). Attentional capture helps explain why moral and emotional content go viral. Journal of Experimental Psychology: General, 149(4), 746-756. https://doi. org/10.1037/xge0000673

Brevers, D., \& Turel, O. (2019). Strategies for self-controlling social media use: Classification and role in preventing social media addiction symptoms. Journal of Behavioral Addictions, 8(3), 554-563. https:// doi.org/10.1556/2006.8.2019.49

Chan, E., \& Briers, B. (2019). It's the end of the competition: When social comparison is not always motivating for goal achievement. Journal of Consumer Research, 46(2), 351-370. https://doi.org/10.1093/jcr/ ucy075

Cohen, J. Y. (2015). Dopamine and serotonin signals for reward across time scales. Science, 350(6256), 47-48. https://doi.org/10.1126/ science.aad3003

de Vries, D. A., Möller, A. M., Wieringa, M. S., Eigenraam, A. W., \& Hamelink, K. (2018). Social comparison as the thief of joy: Emotional consequences of viewing strangers' Instagram posts. Media Psychology, 21(2), 222-245. https://doi.org/10.1080/15213 269.2016.1267647

DeRusso, A. L., Fan, D., Gupta, J., Shelest, O., Costa, R. M., \& Yin, H. H. (2010). Instrumental uncertainty as a determinant of behavior under interval schedules of reinforcement. Frontiers in Integrative Neuroscience, 4(17), 1-8. https://doi.org/10.3389/fnint.2010.00017

Deters, F. G., \& Mehl, M. R. (2013). Does posting Facebook status updates increase or decrease loneliness? An online social networking experiment. Social Psychological and Personality Science, 4(5), 579586. https://doi.org/10.1177/1948550612469233

Digital Information World. (2019). Revealed: The social media platforms that make the most revenue off their users. Digital Information World. Retrieved September 2, 2020, from https://www.digitalinformat ionworld.com/2019/12/revenue-per-social-media-user.html

Dindar, M., \& Yaman, N. D. (2018). \#IUseTwitterBecause: Content analytic study of a trending topic in Twitter. Information Technology and People, 31(1), 256-277. https://doi.org/10.1108/ ITP-02-2017-0029

Docherty, N. (2020). Facebook's ideal user: Healthy habits, social capital, and the politics of well-being online. Social Media and Society, 6(2), 1-13. https://doi.org/10.1177/2056305120915606

eMarketer. (2019). Social media activities on select social networks by social media users in the United States in February 2019 [Graph]. Statista. Retrieved September 20, 2020, from https://www-statista-com. libproxy1.usc.edu/statistics/200843/social-media-activities-byplatform-usa/

eMarketer. (2020). US Social Network Ad Revenues, by Company. eMarketer. Retrieved September 20, 2020, from https://forecasts-na1. eMarketer.com/584b26021403070290f93a4a/5851918b0626310 a2c186b10

Evanschitzky, H., Eisend, M., Calantone, R. J., \& Jiang, Y. (2012). Success factors of product innovation: An updated meta-analysis. Journal of Product Innovation Management, 29, 21-37. https://doi. org/10.1111/j.1540-5885.2012.00964.x

Eyal, N. (2014). Hooked: How to build habit-forming products. Penguin.

Fishbein, M., \& Ajzen, I. (2011). Predicting and changing behavior: The reasoned action approach. Taylor \& Francis. 
Fu, S., Li, H., Liu, Y., Pirkkalainen, H., \& Salo, M. (2020). Social media overload, exhaustion, and use discontinuance: Examining the effects of information overload, system feature overload, and social overload. Information Processing and Management, 57(6), 1-15. https://doi. org/10.1016/j.ipm.2020.102307

Garaialde, D., Bowers, C. P., Pinder, C., Shah, P., Parashar, S., Clark, L., \& Cowan, B. R. (2020). Quantifying the impact of making and breaking interface habits. International Journal of Human-Computer Studies, 142, 1-9. https://doi.org/10.1016/j.ijhcs.2020.102461

Gardner, B., Abraham, C., Lally, P., \& de Bruijn, G. J. (2012). Towards parsimony in habit measurement: Testing the convergent and predictive validity of an automaticity subscale of the Self-Report Habit Index. International Journal of Behavioral Nutrition and Physical Activity, 9(1), 1-12. https://doi.org/10.1186/1479-5868-9-102

Hall Jeffrey, A., Xing Chong, Ross Elaina, M., \& Johnson Rebecca, M. (2019). Experimentally manipulating social media abstinence: results of a four-week diary study. Media Psychology, 1-17. http://dx.doi. org/10.1080/15213269.2019.1688171.

Hatmaker, T. (2020). Changing How Retweets Work, Twitter Seeks to Slow Down Election Misinformation. Techcrunch. Retrieved October 28 2020 from https://techcrunch.com/2020/10/09/twitter-retweetchanges-quote-tweet-election-misinformation/

Itzchakov, G., Uziel, L., \& Wood, W. (2018). When attitudes and habits don't correspond: Self-control depletion increases persuasion but not behavior. Journal of Experimental Social Psychology, 75(481), 1-10. https://doi.org/10.1016/j.jesp.2017.10.011

Jaffray, P., \& eMarketer. (2020). Most popular social networks of teenagers in the United States from fall 2012 to fall 2019 [Graph]. Statista. Retrieved September 18, 2020, from https://www-statista-com. libproxy2.usc.edu/statistics/250172/social-network-usage-of-usteens-and-young-adults/

James, W. (1890). Principles of psychology, vol. 1. Holt.

Ji, M. F., \& Wood, W. (2007). Purchase and consumption habits: Not necessarily what you intend. Journal of Consumer Psychology, 17(4), 261-276. https://doi.org/10.1016/S1057-7408(07)70037-2

Junco, R., Heiberger, G., \& Loken, E. (2011). The effect of Twitter on college student engagement and grades. Journal of Computer Assisted Learning, 27(2), 119-132. https://doi. org/10.1111/j.1365-2729.2010.00387.x

Kim, M. (2014). The effects of external cues on media habit and use: Push notification alerts and mobile application usage habits [Dissertation, Michigan State University]. Retrieved September 2, 2020, from https://d.lib.msu.edu/etd/3263/datastream/OBJ/download/The effects_of_external_cues_on_media_habit_and_use___push_notif ication_alerts_and_mobile_application_usage_habits.pdf

Köse, D. B. (2020). Rolling or scrolling? The effect of content type on habitual use of Facebook. In Twenty-Third Pacific Asia Conference on Information Systems 2020 Proceedings, Dubai. https://aisel.aisnet.org/ pacis2020/57

Kosslyn, J. (2018). The internet needs more friction. Vice. Retrieved October 28, 2020 from https://www.vice.com/en/article/3k9q33/ the-internet-needs-more-friction

Labrecque, J. S., Wood, W., Neal, D. T., \& Harrington, N. (2017). Habit slips: When consumers unintentionally resist new products. Journal of the Academy of Marketing Science, 45, 119-133. https://doi. org/10.1007/s11747-016-0482-9

Lally, P., Van Jaarsveld, C. H., Potts, H. W., \& Wardle, J. (2010). How are habits formed: Modelling habit formation in the real world. European Journal of Social Psychology, 40(6), 998-1009. https://doi. org/10.1002/ejsp.674

LaRose, R. (2010). The problem of media habits. Communication Theory, 20(2), 194-222. https://doi.org/10.1111/j.1468-2885.2010.01360.x

LaRose, R. (2015). The psychology of interactive media habits. In S. S. Sundar (Ed.), The handbook of the psychology of communication
technology(pp.365-383).JohnWiley\&Sons.https://doi.org/10.1002/ 9781118426456.ch16

LaRose, R., Kim, J., \& Peng, W. (2010). Social networking: Addictive, compulsive, problematic, or just another media habit? In Z. Papacharissi (Ed.), A networked self: Identity, community, and culture on social network sites (pp. 67-89). Routledge.

Lee, E., Lee, J. A., Moon, J. H., \& Sung, Y. (2015). Pictures speak louder than words: Motivations for using Instagram. Cyberpsychology, Behavior, and Social Networking, 18(9), 552-556. https://doi. org/10.1089/cyber.2015.0157

Lewis, S. C. (2015). Reciprocity as a key concept for social media and society. Social Media and Society, 1(1), 1-2. https://doi.org/10.1177/20563 05115580339

Limayem, M., \& Cheung, C. M. (2008). Understanding information systems continuance: The case of Internet-based learning technologies. Information and Management, 45(4), 227-232. https://doi. org/10.1016/j.im.2008.02.005

Limayem, M., Hirt, S. G., \& Cheung, C. M. (2007). How habit limits the predictive power of intention: The case of information systems continuance. MIS Quarterly, 31(4), 705-737. https://www.jstor.org/stabl e/25148817

Lin, P. Y., Wood, W., \& Monterosso, J. (2015). Healthy eating habits protect against temptations. Appetite, 103, 432-440. https://doi. org/10.1016/j.appet.2015.11.011

Lindström, B., Bellander, M., Chang, A., Tobler, P. N., \& Amodio, D. M. (2019). A computational reinforcement learning account of social media engagement. PsyArXiv. https://doi.org/10.31234/osf.io/78mh5

Linshi, J. (2015). How to stop Facebook from killing your data plan. Time. Retrieved September 2, 2020, from https://time.com/3924162/ facebook-autoplay-ads-off/\#: :text=Like\%20Facebook's\%20aut oplay $\% 20$ videos\%2C\%20whichdisable\%20or\%20limit\%20aut o\%2Dplay

Luqman, A., Cao, X., Ali, A., Masood, A., \& Yu, L. (2017). Empirical investigation of Facebook discontinues usage intentions based on SOR paradigm. Computers in Human Behavior, 70, 544-555. https://doi. org/10.1016/j.chb.2017.01.020

Makowski, D., Ben-Shachar, M. S., Patil, I., \& Lüdecke, D. (2020). Methods and algorithms for correlation analysis in R. Journal of Open Source Software, 5(51), 1-4. https://doi.org/10.21105/joss.02306

Malik, M. M., \& Pfeffer, J. (2016). Identifying platform effects in social media data. In Proceedings of the 10th International Conference on Web and Social Media, pp. 241-249. Retrieved September 2, 2020, from https://www.mominmalik.com/malik_icwsm2016.pdf

Mazar, A., Itchakov, G., Lieberman, A., \& Wood, W. (2020). The unintentional nonconformist: Habits promote resistance to social influence. Manuscript under editorial review.

Mediakix. (2019). How many people use Instagram stories? Mediakix., Retrieved September 2, 2020, from https://Mediakix.com/blog/ how-many-people-use-instagram-stories/

Meier, A., Reinecke, L., \& Meltzer, C. E. (2016). Facebocrastination? Predictors of using Facebook for procrastination and its effects on students' well-being. Computers in Human Behavior, 64, 65-76. https://doi.org/10.1016/j.chb.2016.06.011

Murray, K. B., \& Häubl, G. (2007). Explaining cognitive lock-in: The role of skill-based habits of use in consumer choice. Journal of Consumer Research, 34(1), 77-88. https://doi.org/10.1086/513048

Nah, F.-F.-H. (2004). A study on tolerable waiting time: How long are web users willing to wait? Behaviour \& Information Technology, 23(3), 153-163. https://doi.org/10.1080/01449290410001669914

Newton, C. (2016). Why Vine Died. The Verge.com. Retrieved September 20, 2020, from https://www.theverge.com/2016/10/28/13456208/ why-vine-died-twitter-shutdown

Noble, S. U. (2018). Algorithms of oppression: How search engines reinforce racism. New York University Press. 
Oh, S., \& Syn, S. Y. (2015). Motivations for sharing information and social support in social media: A comparative analysis of Facebook, Twitter, Delicious, YouTube, and Flickr. Journal of the American Society for Information Science and Technology, 64(10), 2045-2060. https://doi. org/10.1002/asi.23320

Ortiz-Ospina, E. (2019). The rise of social media. Our World in Data. Retrieved September 18, 2020, from https://ourworldindata.org/ rise-of-social-media\#licence

Parker, H. J., \& Flowerday, S. V. (2020). Contributing factors to increased susceptibility to social media phishing attacks. South African Journal of Information Management, 22(1), 1-10. https://doi.org/10.4102/ sajim.v22i1.1176

Perloff, R. M. (2014). Social media effects on young women's body image concerns: Theoretical perspectives and an agenda for research. Sex Roles, 71(11-12), 363-377. https://doi.org/10.1007/s11199-014-0384-6

Perrin, A., \& Anderson, M. (2019). Share of U.S. adults using social media, including Facebook, is mostly unchanged since 2018. Pew Research Center. Retrieved September 4, 2020, from https://www.pewre search.org/fact-tank/2019/04/10/share-of-u-s-adults-using-socia I-media-including-facebook-is-mostly-unchanged-since-2018/

Phua, J., Jin, S. V., \& Kim, J. J. (2017). Gratifications of using Facebook, Twitter, Instagram, or Snapchat to follow brands: The moderating effect of social comparison, trust, tie strength, and network homophily on brand identification, brand engagement, brand commitment, and membership intention. Telematics and Informatics, 34(1), 412-424. https://doi.org/10.1016/j.tele.2016.06.004

Polites, G. L., \& Karahanna, E. (2012). Shackled to the status quo: The inhibiting effects of incumbent system habit, switching costs, and inertia on new system acceptance. MIS Quarterly, 3(1), 21-42. https:// doi.org/10.2307/41410404

Quinn, J. M., Pascoe, A., Wood, W., \& Neal, D. T. (2010). Can't control yourself? Monitor those bad habits. Personality and Social Psychology Bulletin, 36(4), 499-511. https://doi.org/10.1177/0146167209360665

Rhodes, L., \& Orlowski, J. (2020). The Social Dilemma [Documentary]. Exposure Labs; Argent Pictures; The Space Program, Netflix.

Rusz, D., Le Pelley, M. E., Kompier, M. A. J., Mait, L., \& Bijleveld, E. (2020). Reward-driven distraction: A meta-analysis. Psychological Bulletin, 146(10), 872-899. https://doi.org/10.1037/bul0000296

Ryan, T., Chester, A., Reece, J., \& Xenos, S. (2014). The uses and abuses of Facebook: A review of Facebook addiction. Journal of Behavioral Addictions, 3(3), 133-148. https://doi.org/10.1556/jba.3.2014.016

Schnauber-Stockmann, A., \& Naab, T. K. (2019). The process of forming a mobile media habit: Results of a longitudinal study in a real-world setting. Media Psychology, 22(5), 714-742. https://doi. org/10.1080/15213269.2018.1513850

Schonberg, T., Bakkour, A., Hover, A. M., Mumford, J. A., Nagar, L., Perez, J., \& Poldrack, R. A. (2014). Changing value through cued approach: An automatic mechanism of behavior change. Nature Neuroscience, 17, 625-630. https://doi.org/10.1038/nn.3673

Seo, M., Kim, J., \& Yang, H. (2016). Frequent interaction and fast feedback predict perceived social support: Using crawled and self-reported data of Facebook users. Journal of Computer-Mediated Communication, 21(4), 282-297. https://doi.org/10.1111/jcc4.12160

Smith, A. (2015). U.S. smartphone use in 2015. Pew Research Center Retrieved September 2, 2020, from https://www.pewresearch.org/ internet/2015/04/01/us-smartphone-use-in-2015/

Snap, Inc. (2019). Apposphere: How frequent social media use impacts your daily life and emotions. Snap, Inc. Retrieved September 2, 2020, from https://forbusiness.snapchat.com/blog/apposphere-how-the-appsyou-use-impact-your-daily-life-and-emotions

Southern, M. (2017). Facebook removes ticker news feed for monitoring friends' activity. Search Engine Journal. Retrieved October 28, 2020 from https://www.searchenginejournal.com/facebook-removesticker-news-feed-monitoring-friends-activity/227233/
Spottswood, E. L., \& Hancock, J. T. (2016). The positivity bias and prosocial deception on Facebook. Computers in Human Behavior, 65, 252259. https://doi.org/10.1016/j.chb.2016.08.019

Statista. (2020). Why do you use Instagram? [Graph]. Statista. Retrieved September 16, 2020, from https://www-Statista.com.libpr oxy1.usc.edu/forecasts/1088842/reasons-for-instagram-usage -in-the-us

Stawarz, K., Cox, A. L., \& Blandford, A. (2015). Beyond self-tracking and reminders: Designing smartphone apps that support habit formation. In Proceedings of the 33rd Annual ACM Conference on Human Factors in Computing Systems, USA, pp. 2653-2662. https://doi. org/10.1145/2702123.2702230

Tam, L., Wood, W., \& Ji, M. F. (2009). Brand loyalty is not habitual. In D. J. Maclnnis, C. W. Park, \& J. R. Priester (Eds.), Handbook of brand relationships (pp. 5-23). M.E. Sharpe.

Thorson, K., Cotter, K., Medeiros, M., \& Pak, C. (2019). Algorithmic inference, political interest, and exposure to news and politics on Facebook. Information, Communication \& Society, 1-18. http://dx.doi. org/10.1080/1369118x.2019.1642934.

Torkjazi, M., Rejaie, R., \& Willinger, W. (2009). Hot today, gone tomorrow: On the migration of MySpace users. In Proceedings of the 2nd ACM Workshop on Online Social Networks, USA, pp. 43-48. https://doi. org/10.1145/1592665.1592676

Tromholt, M. (2016). The Facebook experiment: Quitting Facebook leads to higher levels of well-being. Cyberpsychology, Behavior, and Social Networking, 19(11), 661-666. https://doi.org/10.1089/ cyber.2016.0259

Turel, O., \& Serenko, A. (2012). The benefits and dangers of enjoyment with social networking websites. European Journal of Information Systems, 21(5), 512-528. https://doi.org/10.1057/ejis.2012.1

Utz, S. (2015). The function of self-disclosure on social network sites: Not only intimate, but also positive and entertaining self-disclosures increase the feeling of connection. Computers in Human Behavior, 45, 1-10. https://doi.org/10.1016/j.chb.2014.11.076

Vally, Z., \& D'Souza, C. G. (2019). Abstinence from social media use, subjective well-being, stress, and loneliness. Perspectives in Psychiatric Care, 55(4), 752-759. https://doi.org/10.1111/ppc.12431

van Deursen, A. J., Bolle, C. L., Hegner, S. M., \& Kommers, P. A. (2015). Modeling habitual and addictive smartphone behavior: The role of smartphone usage types, emotional intelligence, social stress, self-regulation, age, and gender. Computers in Human Behavior, 45 , 411-420. https://doi.org/10.1016/j.chb.2014.12.039

Vanman, E. J., Baker, R., \& Tobin, S. J. (2018). The burden of online friends: The effects of giving up Facebook on stress and well-being. The Journal of Social Psychology, 158(4), 496-507. https://doi. org/10.1080/00224545.2018.1453467

Venkatesh, V., Thong, J. Y., \& Xu, X. (2012). Consumer acceptance and use of information technology: Extending the unified theory of acceptance and use of technology. MIS Quarterly, 36(1), 157-178. https://doi.org/10.2307/41410412

Verduyn, P., Lee, D. S., Park, J., Shablack, H., Orvell, A., Bayer, J., Ybarra, O., Jonides, J., \& Kross, E. (2015). Passive Facebook usage undermines affective well-being: Experimental and longitudinal evidence. Journal of Experimental Psychology: General, 144(2), 480-488. https:// doi.org/10.1037/xge0000057

Verduyn, P., Ybarra, O., Résibois, M., Jonides, J., \& Kross, E. (2017). Do social network sites enhance or undermine subjective well-being? A critical review. Social Issues and Policy Review, 11(1), 274-302. https:// doi.org/10.1111/sipr.12033

Vernuccio, M., Pagani, M., Barbarossa, C., \& Pastore, A. (2015). Antecedents of brand love in online network-based communities. A social identity perspective. Journal of Product and Brand Management, 24(7), 706-719. https://doi.org/10.1108/ JPBM-12-2014-0772 
Verpanken, B., Roy, D., \& Whitmarsh, L. (2019). Cracks in the wall: Habit discontinuities as vehicles for behavior change. In B. Verplanken (Ed.), The psychology of habit (pp. 189-205). Springer. https://doi. org/10.1007/978-3-319-97529-0_11

Vincent, J. (2020). Twitter is Bringing its 'read before you retweet' prompt to all users. The Verge. Retrieved October 28, 2020 from https://www. theverge.com/2020/9/25/21455635/twitter-read-before-youtweet-article-prompt-rolling-out-globally-soon

Vishwanath, A. (2015). Habitual Facebook use and its impact on getting deceived on social media. Journal of Computer-Mediated Communication, 20(1), 83-98. https://doi.org/10.1111/jcc4.12100

Vishwanath, A., Harrison, B., \& Ng, Y. J. (2018). Suspicion, cognition, and automaticity model of phishing susceptibility. Communication Research, 45(8), 1146-1166. https://doi.org/10.1177/0093650215 627483

Vishwanath, B., Mislove, A., Cha, M., \& Gummadi, K. P. (2009). On the evolution of user interaction in Facebook. In Proceedings of the 2nd ACM workshop on online social networks, USA, pp. 37-42. https://doi. org/10.1145/1592665.1592675

Vosoughi, S., Roy, D., \& Aral, S. (2018). The spread of true and false news online. Science, 359(6380), 1146-1151. https://doi.org/10.1126/ science.aap9559
Wang, J., Zheng, B., Liu, H., \& Yu, L. (2020). A two-factor theoretical model of social media discontinuance: role of regret, inertia, and their antecedents. Information Technology and People. Advance online publication. https://doi.org/10.1108/ITP-10-2018-0483

We Are Social, DataReportal, \& Hootsuite. (2020). Daily time spent on social networking by internet users worldwide from 2012 to 2019 (in minutes) [Graph]. Statista. Retrieved September 12, 2020, from https:// www-statista-com.libproxy2.usc.edu/statistics/433871/daily-socia I-media-usage-worldwide/

Wood, W., \& Rünger, D. T. (2016). Psychology of habit. Annual Review of Psychology, 67, 289-314. https://doi.org/10.1146/annurev-psych $-122414-033417$

Wood, W., Tam, L., \& Witt, M. G. (2005). Changing circumstances, disrupting habits. Journal of Personality and Social Psychology, 88(6), 918-933. https://doi.org/10.1037/0022-3514.88.6.918

Zell, A. L., \& Moeller, L. (2018). Are you happy for me ... on Facebook? The potential importance of "likes" and comments. Computers in Human Behavior, 78, 26-33. https://doi.org/10.1016/j. chb.2017.08.050 